\title{
O Atlas Imperio do Brazil de 1868: uma ação pedagógica na construção de um Estado Nacional e de uma Nação
}

\author{
The Brazilian Empire Atlas (1868): a pedagogical \\ undertaking in the construction of a National State \\ and a Nation
}

\section{Atlas Empire du Brésil (1868): une action pédagogique pour la construction d'un État National et d'une Nation}

Jorge Luiz Barcellos da Silva

Universidade Federal de São Paulo

jorge.barcellos@unifesp.br

\begin{abstract}
Resumo
O objetivo desse texto é examinar como o Atlas Imperio do Brazil constituiu-se em uma ação pedagógica na construção identitária do Estado Nacional e da nação brasileira. Referenciado nos estudos de Lefebvre (1987), Dardel (2011) e Moreira (2004), refletimos sobre a premissa de que construção da identidade é também a construção de uma territorialidade. A essas preocupações somamos as colocações de Thissé (2014) a respeito de formações de identidades nacionais no século XIX. Consideramos as proposições de um conjunto de elementos simbólicos e materiais pelo Estado Imperial brasileiro, no sentido de difundir uma imagem do território e propor que todos os indivíduos, nas suas diferenças, fossem comuns à nação imaginada (Anderson, 2008). As interpretações de mapas foram efetivadas a partir de apreciações de Harley (2005), Jacob (1998), Wood (2012) e Black (2005). Os resultados encontrados evidenciam que a ordem tópica dos fenômenos representados foi levada em conta na construção do Estado Nacional e do sentimento de pertencimento da nação em formação.
\end{abstract}

Palavras-chave: Atlas, mapas, identidade, territorialidade.

\section{Abstract}

This paper examines how the Brazilian Empire Atlas had a pedagogical role in constructing the identity of the Brazilian National State and nation. Based on 
Lefebvre (1987), Dardel (2011) and Moreira (2004), we ponder the notion that identity-building also entails building a territoriality. The discussion includes Thissé's (2014) observations on the formation of national identities in the 19th century. In that framework, we analyze how the Brazilian Imperial Government proposed a symbolic and material set designed to propagate a particular image of its territory and to imply that all of its different individuals were part of the imagined nation (Anderson, 2008). The maps are interpreted based on the findings of Harley (2005), Jacob (1998), Wood (2012) and Black (2005). The results show that the spatial organization of phenomena had its part in the construction of the National Estate and in fostering a feeling of belonging to the budding nation.

Keywords: Atlas, maps, identity, territoriality.

\begin{abstract}
Résumé
Cet article examine comment l'Atlas Empire du Brésil s'est constitué en action pédagogique pour la construction identitaire de l'État National et de la nation brésilienne. On s'appuie sur les études de Lefebvre (1987), Dardel (2011) et Moreira (2004) pour réfléchir sur la prémisse que la construction de l'identité soit aussi la construction d'une territorialité. À ces préoccupations on ajoute celles de Thissé (2014) concernant les formations des identités nationales au XIXème. On considère que l'État Impérial brésilien proposa un ensemble d'éléments symboliques et matériaux, ayant pour but de diffuser une image du territoire et de proposer que tous les individus, dans ses différences, fussent communs à la nation imaginé (Anderson, 2008). Nôtres interprétations des cartes se font sur les considérations de Harley (2005), Jacob (1998), Wood (2012) et Black (2005). Pour les résultés, on trouve que l'ordre topique des phénomènes représentés fut considérée dans la construction de l'État National et du sentiment d'appartenance à la nation qui se formait.
\end{abstract}

Mots-clés: Atlas, cartes, identité, territorialité.

\title{
Introdução
}

Neste artigo procuramos identificar como os mapas representando o território nacional do Atlas Imperio do Brazil de 1868 de Candido Mendes de Almeida se consubstanciaram em uma ação pedagógica na construção do Estado-Nacional Imperial brasileiro e na distinção da nação. Para tal, tomamos como referência as ponderações de Lefebvre (1987), Dardel (2011) e Moreira (2004) para refletir sobre a premissa de que a construção da identidade é também a construção de uma territorialidade e, assim, contribuir no reconhecimento da geograficidade da qual fazemos parte.

A essas ponderações somamos as colocações de Thissé (2014), a respeito de formações de identidades nacionais na Europa ao longo do século XIX. Essas inflexões subsidiaram nossas leituras a respeito da constituição do Estado Imperial brasileiro, no mesmo período, pois consideramos como notório que, em função de suas necessidades de afirmação, ocorreu a proposição de um conjunto de elementos materiais e simbólicos, visando a construção de um sentimento de pertencimento.

No que se refere ao tratamento dos mapas, entendendo-os como formas de organização do pensamento que a experiência de construção do Brasil nos legou, 
buscamos desvelar o jogo de significados que possuem. Nesse sentido recorremos a algumas ponderações sobre representações cartográficas de Harley (2005), Jacob (1996), Wood (2013) e de Black (2005). Elas subsidiaram nossas indagações sobre como a ordem tópica dos fenômenos representados foi levada em conta na consolidação de uma identidade nacional.

Nosso interesse aqui é o de apresentar problematizações, indicando que no processo de construção identitária, isto é, na construção do território brasileiro e do sentimento de pertencimento dos brasileiros, o estar localizado e os discursos sobre esse fenômeno implicam outro dimensionamento entre nós e os outros.

Nesse sentido essas preocupações nos inserem em um eixo que justifica a maneira pela qual elaboramos as perguntas para as preocupações de ordem espacial, no âmbito do sujeito que constrói a ação. Pensar como se formulam leituras geográficas, é refletir e sistematizar o instrumental que nos ajuda a desvendar o conjunto de ideias que fundamenta os indivíduos; é o que explicitamos na primeira parte deste artigo. As leituras dos mapas do Brasil contidos no referido atlas e suas respectivas interpretações são apresentados na sequência.

\section{De onde falamos para ponderar sobre identidade nacional e dimensão espacial}

$\mathrm{Na}$ analise da delicada operação de construção da identidade nacional que se desdobrou no Brasil ao longo do século XIX, inicialmente, é possível constatar que as diferenças identitárias dos indivíduos (os europeu, os negros e os índios) foram tratadas com o objetivo de se congregar uma unidade (THISSÉ, 2014). Por sua vez a constatação dessa dinâmica exigiu uma preocupação de ordem espacial, pois ao se estabelecer as linhas que separam as diferenças (as fronteiras) se está localizando onde estão os sujeitos e seus processos. Isso configura - no passado e no presente - um denso constructo de pertencimento ao/no reconhecimento do Estado soberano.

Entendemos que a construção da identidade nacional e da população se tratou de um processo lento, no qual o Estado Imperial - em formação - pari passu, foi criando um conjunto de elementos materiais e simbólicos no sentido de propor a perspectiva de que todos os indivíduos, nas suas diferenças, são comuns à nação (imaginada), como pontua Anderson (2008).

$\mathrm{Na}$ construção do Estado-Nação, tanto a "máquina de Estado", como as elites que, de uma maneira ou de outra, construíram a chamada identidade nacional, cumpriram um verdadeiro programa a ser percorrido. Criou-se uma compreensão coletiva por meio de romances, do estabelecimento de datas comemorativas, de culto de heróis, de obras de arte, de hinos, de identificação de paisagens (lugares) etc. Esses artefatos culturais constituíram-se em ações que buscavam criar os laços simbólicos que pudessem unir a todos.

A elite pensante se vê diante da necessidade premente de criar interpretações para se contrapor a uma situação real de discussões que envolviam a possibilidade de quebra 
da unidade do império. Ao mesmo tempo encarna o espírito de uma época, que vem da América do Norte e da Europa, que assinala a necessidade dos grupos sociais saírem do estado de barbárie, visando à civilização. Essa transformação seria o conduto para o progresso. Era preciso construir referências (materiais e simbólicas) que passassem a ser mediadoras para se conceber o Brasil.

Quando indicamos as referências materiais e simbólicas para se pensar o Brasil estamos nos referindo aos inúmeros documentos portadores de delineamentos e divulgações de limites e características de seus territórios assim como reconhecimentos de diferentes populações. São exemplos dessas mediações o mapa de Niemayer de 1846 (PEIXOTO, 2004), os romances de José de Alencar e suas descrições dos lugares e dos tipos humanos (NAXARA, 2004); as referenciações de personalidades a partir de entidades como IHGB (ENDERS, 2000), as mensagens da pintura (CIPINIUK, 2003), como aquela criada por Pedro Américo, na tela Tiradentes, em 1893, etc..

Entendemos que esses artefatos culturais possuem referências locacionais. Eles fazem uma exposição didática, de ordem geográfica, sobre o significado dos lugares na vida das pessoas. Isso, concordando, com o que escreveu Santos (2014, p. 17): "referese à condição do discurso geográfico estar associado ao conjunto de relações simbólicas que nos permitem construir as noções básicas de localização e pertencimento" .

Localizar os sujeitos e processos dimensionados pela sua geograficidade nos possibilita outra senda analítica: aquela que relaciona saber geográfico com o sentido dos indivíduos estarem no mundo e, nessa proporção, refletir o que são. Nesse sentido, antes de adentrarmos na processualidade da fabricação da identidade nacional e de seus habitantes, da qual o atlas de Candido Mendes de Almeida fazia parte, vale apontarmos para um esclarecimento de ordem conceitual: de qual geograficidade estamos acertando?

A noção de geograficidade que pontuamos em nosso estudo se caracteriza, dialogando com as seminais contribuições de DARDEL (2011), pelas preocupações de ordem processual (tempo e espaço como movimento) que dimensionam o homem na Terra e, com o geógrafo Ruy Moreira, pela ampliação de articulações que estabelece, evidenciando determinações concretas que envolvem as relações que os homens estabelecem entre si e com a Natureza.

Nesse sentido nos apoiamos nas ponderações de Moreira (2004, p. 34) que chama a atenção para o fato de que:

A geograficidade é a existência em sua expressão espacial. O ponto ônticoontológico da tradução do metabolismo homem-meio no metabolismo homemespaço [...] A geograficidade é o modo de expressão dessa essência metabólica - a hominização do homem pelo homem através do trabalho - em formas espaciais concretas de existência, algo que difere nos diferentes recortes do território da superfície terrestre.

Esse encaminhamento nos permite inferir que os homens e mulheres, ao se relacionarem entre si e com a natureza por meio do trabalho, vão configurando os 
lugares. Cada grupo responde às demandas em torno de suas necessidades, conforme as condições materiais e, com isso, se distingue dos demais. Essa objetividade vai criando subjetividades, isto é, há uma forte vinculação entre o campo material e simbólico que rege as relações.

As geografias que os homens e mulheres constroem e representam, via discursos geográficos (por exemplo, acadêmicos e escolares), podem permitir diálogos sobre a construção de quem é o outro e quem somos nós, à medida que nos perguntamos sobre o significado de estarmos em algum lugar.

É com essas preocupações que, doravante, ao falarmos em geograficidade, estamos dimensionando o papel que os lugares cumprem na identificação dos territórios e dos homens e mulheres.

No que se vincula ao reconhecimento de territorialidades dos homens e mulheres estamos assinalando ser mais que sua localização geométrica, isto é, exige uma reflexão que supere o simples encontro entre dois pontos numa superfície e que possibilita tratarmos do reconhecimento que cada sujeito tem no seu ir e vir - e, portanto, do seu estar no mundo -, a fim de garantir a manutenção da vida.

Essa atividade implica o entendimento de que a humanidade está carregada de possibilidades e permite apontarmos para o fato de, a cada momento em que os homens e mulheres estão construindo os marcos referenciais que identificam os lugares (para que possam saber onde está o que lhe é significativo), reconhecermos que estão concomitantemente construindo as suas próprias identidades. Por isso podemos dizer que, ao construírem as suas geografias diárias, constroem distinções do ali e do acolá, assim como entre o que eu sou e quem é o outro.

Lefebvre (1987, p. 34) nos dá condições de aprofundar a discussão:

No começo era o topos. E o topos indicava o mundo, pois era lugar; não estava em Deus, não era Deus, pois Deus não tem lugar e jamais o teve. E o topos era o Logos, mas o Logos não era Deus, pois era o que tem lugar. O Topos, na verdade, era poucas coisas: a marca, a re-marca. Para marcar, houve traços, dos animais e de seus percursos; depois, sinais: um seixo, uma árvore, um galho quebrado, um cairn. As primeiras inscrições, os primeiros escritos. Por pouco que fosse, o Topos já era "o homem”. Assim como o sílex seguro pela mão, como a vara erguida com boa ou má intenção. Ou a primeira palavra: o Topos era o verbo; algo mais: a ação, "Am Anfarg war die Tat". E algo menos: o lugar dito e marcado, fixado. Assim o verbo não se fez carne, mas lugar e nãolugar. Partir do lugar, mental e social, lugar da identidade e da diferença, lugar marcado (logo destacado) e nomeado (lugar dito), logo ligado e religado - por que não? A direção e a orientação, o trajeto e o percurso, vão de um lugar para outro. Existe, a partir de então, o outro lugar (marcado, separado, distinto, mas o mesmo: a isotopia) e o lugar outro (marcado, ligado, alcançado: a heterotopia). E finalmente e também, há o alhures e lugar nenhum, o próximo e o distante (a ordem próxima e a ordem ampla), isto é, o outro e o estranho. 
Fica patente de que é na relação dos homens com o mundo, via referências locacionais (as marcas e remarcas), que suas identidades vão se constituindo. A ordem tópica constitui um dos fundamentos do ser.

Simples atos como nomear os lugares, definir o que está próximo, o que está distante, as direções, as orientações, os caminhos entre um lugar e outro são referências de localização. Saber onde está a água, o perigo, a caverna, o local da festa, da comida, da referência mítica, do trabalho, caracteriza as ações cotidianas fundadas na cultura que cada grupo apresenta.

O interessante, nesse movimento, é observar o fato de que, além da diversidade de modos como cada cultura se realiza no cotidiano, todas são fundadas com base no topos, isto é, todas se revelam, se determinam pela forma e conteúdo considerando a lógica de suas arrumações territoriais.

A dimensão topológica é condição sine qua non da existência. Toda cultura, isto é, todo modo de vida, para poder se realizar, materializa-se como algum lugar e, por conseguinte, as pessoas ao se relacionarem entre si e com a natureza, materializamse como elementos que compõem os lugares. Por esse motivo, podemos dizer que as pessoas dão os sentidos às ordens territoriais que emanam das relações apontadas e fundamentalmente se reconhecem ali e acolá. A superação das necessidades que os homens têm em seu cotidiano implica um movimento de conhecer e reconhecer, a todo instante, os lugares. Ir e vir pelo mundo, movimentar-se, ordenar-se territorialmente, elaborar a manutenção da existência, portanto, significa a construção de suas geografias.

É como um desdobramento de toda essa reflexão que evidenciamos o fato de, em razão do movimento de dar significados e ressignificados aos lugares, pela via da toponímia, pelas marcas que vão deixando nos deslocamentos de um lugar para o outro ou pelo caminho do estabelecimento de diferenças por linhas demarcatórias (as fronteiras), ser necessária a criação de sinais (marcas, símbolos) que caracterizem o grau de (re)conhecimento que os sujeitos têm dos lugares nesse processo de identificar o lugar marcado e nomeado. (SILVA, 2006).

Com essas preocupações efetivamos as leituras geográficas do atlas de Candido Mendes de Almeida. Consideramos que a Geografia trata da identificação de ordem topológica das coisas. Trata-se de pensarmos que a posição relativa de cada coisa (a coexistência, por exemplo, de rios, córregos, florestas, plantações, caminhos, tribos indígenas, fazendas, montanhas, cumeada de serras, planícies, ilhas, lagos, fundos de vales, garimpos, vilarejos, arruamentos, portos etc.) é importante na definição do significado dos processos (os movimentos que dão significado aos) nos diferentes lugares.

Os lugares (e suas localizações) - reconhecidos pelos mapas contidos no atlas de Candido Mendes deixam de ser o substrato material (o chão inerte) que serve de base para que a história aconteça. Eles passam a ser a condição que se confunde com a própria história. Assim, dimensionar os processos a partir dos lugares e suas representações é pensá-los a partir de suas localizações. 
A essas considerações do fazer geográfico somamos as ponderações de Black (2005, p. 101) (grifo nosso), a respeito do papel da difusão de atlas no período. De acordo com esse autor "o desenvolvimento de Estados nacionais podia ser mostrados por meio dos atlas históricos" [e geográficos], "e os sistemas educacionais nacionais desempenhavam papel importante na propagação de tais obras”. Trata-se de um estudo que além de indagar, por exemplo, sobre o papel de imagens como meio de criar percepções de poder, nos dá muitos elementos para adensar as questões que envolvem a compreensão do papel da dimensão espacial das relações sociais e a construção identitária de nossa sociedade.

Nesse sentido vale ainda esclarecer outro aporte que nos ajuda a organizar a abordagem de um documento como o atlas. Buscamos em Certau (1998, p. 261) (grifo nosso) um fundamento para a compreensão de artefato cultural. Há fortes indícios de que o atlas foi pensado como um documento que seria "capaz de reformar a sociedade, [...] e a vulgarização escolar [...] os hábitos e costumes que uma elite tivesse com seus produtos $[\ldots][\mathrm{e}][\ldots]$ se a sua difusão cobrisse todo o território, o poder de remodelar toda a nação".

Dito de outro modo, esse artefato cultural ao ser inserido no âmbito escolar se consolidou como um dos marcos necessário para identificar a ordem tópica de processos importantes para a vida material e assim ao ser difundido, parametrizar o entendimento dos limites territoriais do país e dos sentimentos de pertencimento a ele.

Pretendemos que a reflexão evidenciada com as leituras da proposição do atlas de Candido Mendes de Almeida aqui desenvolvida possa incrementar e contribuir para o debate sobre o papel da ordem espacial na construção da identidade do país e da nação.

Como de praxe, no IHGB, as obras relacionadas ao Brasil eram submetidas a análises por associados designados previamente. Os pareceres, ao apresentarem comentários substantivos, legitimavam e recomendavam a divulgação dos trabalhos, assim como reforçavam a indicação do proponente como membro da instituição. Sobre a participação de intelectuais em agremiações dessa natureza, Santirocchi (2014, p. 72) informa que o nome de Candido Mendes de Almeida como sócio:

já havia sido proposto ao Instituto Histórico desde 1853, por sugestão de Varnhagen a Pedro II, mas só em 25 de setembro de 1868, o sócio Pedro Torquato Xavier de Brito o indicou oficialmente. Nesse ano, havia publicado o Atlas do Império do Brasil, que causou impressão entre os membros do IHGB. Mas, somente dez anos depois, em 1878, seria distinguido com a condição de sócio honorário. Essa demora em ingressar na instituição era o resultado do seu posicionamento político a favor da Igreja, contrariando o Imperador, importantes políticos e intelectuais da época

No que tange ao atlas, à luz das proposições de Harley $(2005$, p. 104) de que "los frontispícios y lãs portadas de muchos atlas [...] definem explícitamente, mediante emblemas en geral claros, tanto la importância ideológica como el alcance práctico de los mapas que contienen [...], encontramos algumas pistas sobre sua natureza e objetivos. 
Os dizeres em letras ornamentadas ( em especial a referência ao imperador) revelam que esse material destinava-se à instrução pública no Império, especialmente a dos alunos do Colégio Imperial Pedro II. Candido Mendes de Almeida (1868, p. 7), considerando existir um "atraso em que se acha o estudo da Geographia entre nós, maxime a do território, moveu-se a dedicar à mocidade estudiosa e esperançosa do Brasil”.

Entre as razões que possam ter influenciado a elaboração do Atlas do Império do Brasil, de 1868, uma delas é o já tão discutido processo de consolidação de uma imagem do território e da nação que o Estado Imperial perseguia. Esse atlas se encaixava no que enfatiza Blake (2005, p. 99): “a conscientização geográfica era vista como um aspecto crucial do nacionalismo; tanto à geografia como à história eram dados papéis importantes na educação cívico-patriota". Deve-se ressaltar que o surgimento do Atlas do Império do Brasil se relaciona a esse continuum. No interior das discussões que envolviam a Monarquia, como exemplos: vinculações entre elites regionais e um Estado em formação; criação de partidos políticos, difusão de ideais republicanos e abolicionistas e as críticas às próprias instituições Imperiais, era essencial criar uma ação pedagogizante sobre a identidade do território e da nação.

O surgimento do Atlas do Império do Brasil veio somar-se ao processo de sistematização do olhar didático que estava em curso. Atuando na escala do desenvolvimento da "cognição" (JACOB, 1996, p. 195), a reprodução de um modelo do desenho territorial do Brasil, e de suas partes constituintes, possibilitou a criação de um documento que, ao ser disseminado, foi identificando uma ordem topológica daquilo que constituiria o país.

Assim como já ocorrera com a criação de uma escola como o Colégio de Pedro II e a difusão de impressos como os compêndios de Geografia (e de outras disciplinas escolares), o advento de uma coleção de mapas - na forma de um atlas - do Império inseria-se no que assinala Black (2005, p. 97): “[...] a implantação da educação [...] [...], organizada em base nacional aumentou [...] [a] [...] conscientização pública mais ampla e criou uma demanda pedagógica pelo atlas". E no plano pedagógico veio com o sentido disciplinador do modo como se deveria entender a ordem territorial do Brasil.

Soma-se a essa importante questão o que José Veríssimo (Apud OLIVEIRA, 1990, p. 80) nos esclarece quanto à ordem política em curso naquele momento:

a Guerra do Paraguai, acordando o sentimento nacional, meio adormecido desde o fim das agitações revolucionárias consequentes à Independência, e de nossas lutas no Prata; a questão do elemento servil, comovendo toda nação e lhe despertando os brios contra a aviltante instituição consuetudinária; a impropriamente chamada questão religiosa, resultante do conflito entre as pretensões de autonomia do catolicismo oficial e as exigências do tradicional regalismo do Estado,[...]; e, finalmente, a guerra franco-alemã com as suas consequências, despertando nossa atenção para uma outra civilização e cultura que a francesa, estimulando novas curiosidades intelectuais. Certos efeitos inesperados da Guerra do Paraguai, como o surdo conflito que, apenas acabada, surgiu entre a tropa demasiado presumida do seu papel e importância 
e os profundos instintos civilistas da Monarquia, não foram sem efeito nesse momento da mentalidade nacional. Também a Revolução Espanhola de 1868 e consequente advento da República em Espanha, a queda do Segundo Império Napoleônico e imediata Proclamação da República em França, em 1870, fizeram ressurgir aqui com maior vigor do que nunca a ideia republicana, que desde justamente esse ano de 70 se consubstanciara num partido com órgão na imprensa da capital do Império. Esta propaganda republicana teve um pronunciado caráter intelectual e interessou grandemente os intelectuais, pode dizer-se que toda a sua parte moça, ao menos. Outro caráter da agitação republicana foi o seu livre-pensamento, se não o seu anticatolicismo, por oposição à Monarquia, oficialmente católica [...] .

Eis o ambiente no qual surgiu o Atlas do Imperio do Brasil. E isso passava pela necessária construção de um sentimento que aglutinasse os súditos em torno de um sentimento de pertencimento à Monarquia.

É nesse sentido que o aparecimento do Atlas do Imperio do Brasil, com as seguintes dimensões: $50 \times 33 \mathrm{~cm}$, portando 37 páginas de textos escritos e 27 ilustrações, se apresentou de forma e conteúdo genuínos. Por um lado, operando no plano simbólico, instituindo os elementos que pudessem amalgamar uma identidade brasileira. Por outro, sistematizando informações como a formalização de linhas de demarcação entre os países da América do Sul, num momento como o do conflito bélico com o Paraguai, pois havia a constatação de que "o Império não dispunha de mapas sobre suas fronteiras." (MAUAD, 1999, p. 220).

Era necessário, em meio às discussões sobre os rumos do país, delinear os limites do lugar geográfico do Estado-nação na perspectiva que desse conta das inovações materiais que estavam em curso, assim como aprofundar o sentimento de patriotismo por meio da fabricação da identidade nacional. de Almeida

Cavenaghi (2010, p. 386) chama a atenção para o fato de que Cândido Mendes realizou seu Atlas [...] em condições adversas. Não havia no Brasil, naquele momento, uma estrutura editorial para impressão de mapas em grande escala e com grande definição [...] [...] Para sanar estes problemas iniciais, fundou um Instituto somente para desenvolver as técnicas e os processos para impressão dos mapas. Seu Instituto Philomathico, foi responsável pela abertura das pranchas litográficas; chapas em pedra com desenhos a serem impressos; como também pela impressão e confecção da totalidade dos mapas do Atlas por ele elaborados [...].

Cândido Mendes de Almeida incumbido de confeccionar "o primeiro [atlas] a escala de empreitada" (1868, p. 1), (grifo nosso), tinha uma clareza meridiana do sentido de se estudar Geografia:

O fruto desses momentos que dispensamos, tem o público na presente obra, cheia de defeitos [...] mas somente inspirada pelo amor do bem, e do vivo interesse que excita em todos os seus filhos uma Pátria querida. Ora essa Pátria 
que he nossa segunda família, desejamos que seja bem conhecida e apreciada por seus filhos, como pelos estranhos. He uma gemma cujas scintillações anciamos que todos contemplem [...] Para este santo desideratum muitíssimo auxilia o inteligente cultivo da Geographia; porque he por este meio que um paiz se faz conhecido, ainda daquelles que o não habitão, e póde fazer valer os seus recursos, e suas qualidades meritórias. A terra foi dada ao homem para lhes proporcionar, com o trabalho, os meios de bem servir a Deos, de acudir e superar as próprias necessidades, e nunca para frui-la egoisticamente [...]. Felizmente podemos acolher com os braços bem abertos todos os que nos demandarem: tão inexgotaveis são as riquezas do nosso solo! Façamos, se for possível, cada vez mais conhecidas as nossas formosas plagas, [...]. Não he um simples deleite o estudo da Geographia. [...] he claro que o povo que deseja na terra representar bem sua missão, satisfazer a idea que tem de realisar, tem de por dúplice obrigação estudar o território que occupa. Ora, esse estudo ainda não o fizemos depois de nossa emancipação política. [...] Como dirigiria bem seu domicilio quem lhe desconhecesse os compartimentos? Como nas duvidas com os visinhos, descriminar o nosso do domínio alheio? [...] O desenvolvimento de qualquer industria existente, a introducção de novas, o alargamento das relações commerciaes, os pontos de defeza de um Paiz, não se poderião estabelecer e crear vantagem, se a Geographia com sua luz não viesse aponta-los á sagacidade e intelligencia de qualquer Governo [...] Eis por tanto demonstrada a necessidade desta sciencia para o Estadista, e para o Legislador. Ella he também indispensável para o Administrador. (1868, p. 7)

A redação do professor de Geografia Candido Mendes de Almeida oferece-nos uma rica concepção de Geografia de uma época. Além de ser um verdadeiro guia para a tomada de decisões referentes às inovações materiais que estavam em curso, tornou-se uma narrativa essencial nas questões relacionadas às apropriações simbólicas.

Ao fazer referência à construção de uma ideia de pátria, paíz, família e regiões, ele o faz articulando tais noções dentro do ideário positivista. Interessa-nos extrair dessas considerações o fato de que suas ponderações são assinaladas como regras sobre como se deveria conceber a nação em formação. E, nesse sentido, fica claro o desdobramento de interesses concretos vinculados a grupos hegemônicos no poder. Havia, como assinalou Chartier (1990, p. 17), uma disputa no que se referem às representações, elas "têm tanta importância como as lutas econômicas para compreender os mecanismos pelos quais um grupo impõe, ou tenta impor, a sua concepção de mundo social, os valores que são só seus e o seu domínio."

No que tange as representações cartográficas escolhidas, por hora basta assinalar que o tratamento acompanha uma das ponderações de Harley $(2005$, p. 62) a respeito de considerarmos os mapas como texto:

los mapas son textos en el mismo sentido en que lo son otros sistemas de signos no verbales como los cuadros, las impresiones, el teatro, el cine, la televisión y la música. Los mapas también comparten muchos intereses comunes con el estudio del libro al exhibir su función textual en el mundo y ser 'sujetos de control bibliográfico, interpretación y análisis histórico'. Los mapas son un 
lenguaje gráfico que se debe decodificar. Son una construcción de la realidad, imágenes cargadas de intenciones y consecuencias que se pueden estudiar en las sociedades de su tiempo. Al igual que los libros, son también producto tanto de las mentes individuales como de los valores culturales más amplios en sociedades específicas.

Ou seja, concebemos que os mapas selecionados caracterizam-se por ser uma interpretação do real a que se referem o que exige do sujeito que deles se utiliza uma capacidade de decodificação e leitura dos signos que o estruturam, assim como a clareza quanto às concepções (para quem, como e por quê?), que estão em jogo na elaboração/ divulgação desse documento.

De posse dessas mediações procuramos não perder de vista o sentido locacional dos fenômenos, suas representações e como esses processos representados se transformaram em outras situações, passíveis de leituras.

Nesse sentido cumpre observar, inicialmente, que os mapas observados, que tratam do território nacional estão enquadrados em uma escala dividida em graus (longitudes e latitudes), cuja referência de longitude é o meridiano do Rio de Janeiro, tal como já acontecera com os padres matemáticos no século XVIII, conforme demonstram os estudos de ALMEIDA (1999). A escala gráfica que aparece nessas ilustrações do atlas, representando o Brasil, assinala as distâncias em léguas (20 léguas a um grau).

Isto posto, acompanhando a ordem dos mapas como aparece na $1^{\text {a }}$ edição, de 1868, vejamos como as leituras geográficas da primeira parte do atlas, contendo um Mappa-mundi e mapas representando o Brasil, elaborados por esse professor de Geografia transformaram-se em veículos para a construção de uma imagem do Estado Nacional e da nação.

\section{Lendo e refletindo sobre a mensagem dos mapas}

Intitulado Mappa-mundi, a Figura 1 apresenta uma visão de conjunto.

Há um subtítulo cuja hierarquização se apresenta respectivamente: Europa, Ásia, África, América Setentrional, América Meridional e Oceania. O subtítulo referente à América Setentrional está destacado por um fundo colorido. Essa representação, conforme assinala Almeida (1868, p. 9) “[...] foi organizado tendo-se á vista diferentes atlas, com especialidade os de Brué, Garnier, Stieler, Houzé, Dufour, Buchon, Delamarche e Colton.”. Utilizando-se de uma "projeção Globular" (RAISZ, 1969, p. 85), o professor de Geografia Candido de Almeida Mendes apresenta a América na escala mundo. Destaque-se que os Estados Nacionais não estão delimitados explicitamente. Todos são apresentados como continentais distintos pelo uso de cores específicas. Nesse agrupamento, o que se enfatiza é a localização de cursos d'água, cordilheiras, montanhas, lagos e a identificação do nome dos países. As formas das massas continentais, assim como as informações a elas relacionadas, refletem o grau de conhecimento dos lugares. Vide o caso da Antártica e o interior do continente da Oceania, africano e asiático. 
Ressalta-se, na porção central inferior da página, a presença de uma representação cartográfica temática evidenciando a "descoberta" da América. Esse desenho, apoiado na interpretação de Varnhagen (apud Almeida, 1868, p. 38-39), expõe com clareza a "derrota de Colombo" na saga de "descoberta" da América.

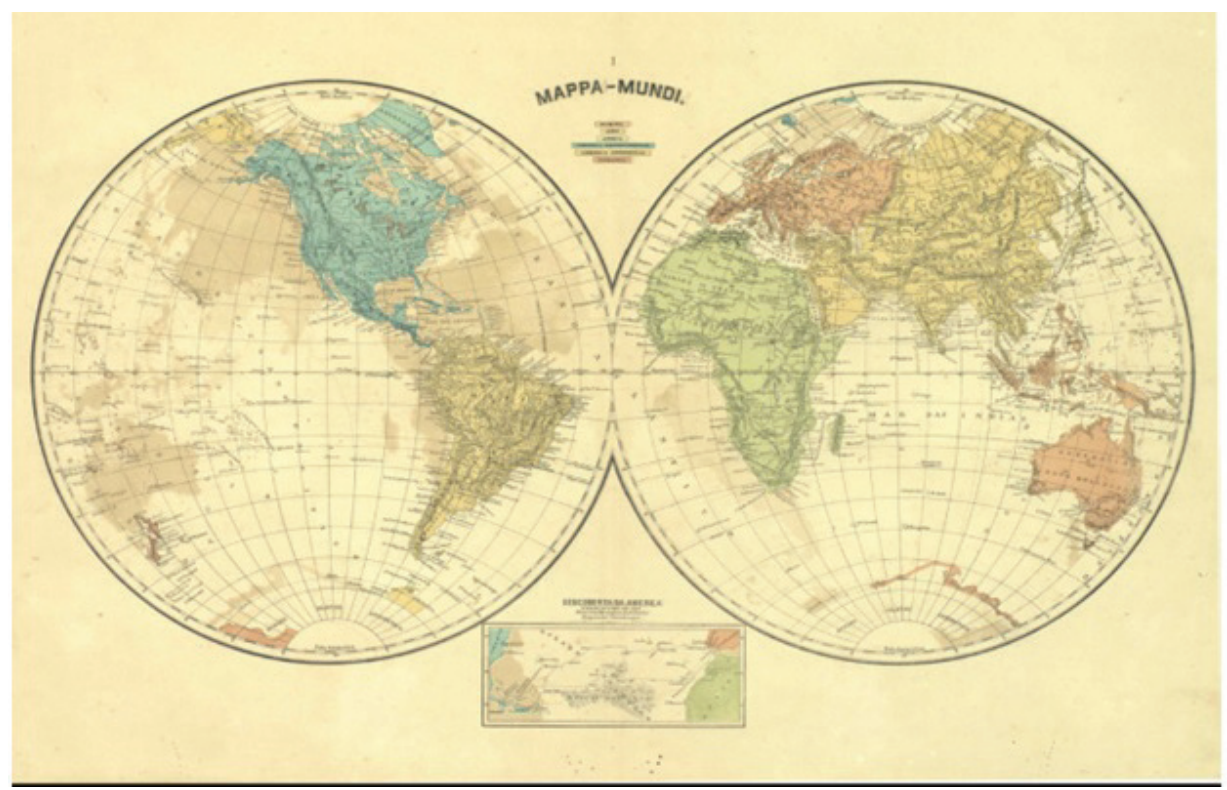

Figura 1. Mappa-mundi, de Candido Mendes de Almeida, 1868. Fonte: Atlas do Imperio do Brazil. Rio de Janeiro, Lithographia do Instituto Philomathico, 1868, p. 38-39. Fonte: Biblioteca digital do Senado <http://www2.senado.leg.br/bdsf/item/id/179473> Acesso em 02 de janeiro de 2013

O segundo mapa (Figura 2), intitulado Império do Brasil (II), é apresentado como aquele em que, pela primeira vez, se tem ideia do todo nacional. Nessa imagem, a distribuição territorial completa das províncias formadoras da unidade do Estado Imperial do Brasil é contemplada na sua integralidade. É possível dimensionar cada parte que compõe o todo. A presença de uma régua de escala permite ao leitor operar no sentido de identificar, localizar e comparar as unidades provinciais. A exposição da rede de fronteiras internas da nação, por meio do uso de um jogo de cores de cada unidade, ressalta o papel das referências locacionais, neste caso, as linhas circundantes de cada unidade do Império. No que se refere ao externo, isto é, o país no mundo, cabe sinalizar que essa representação do Brasil como uma unidade (nacional) apresenta as delimitações com os países vizinhos (novamente pelo uso de cores), assim como suas respectivas identificações e localizações. 


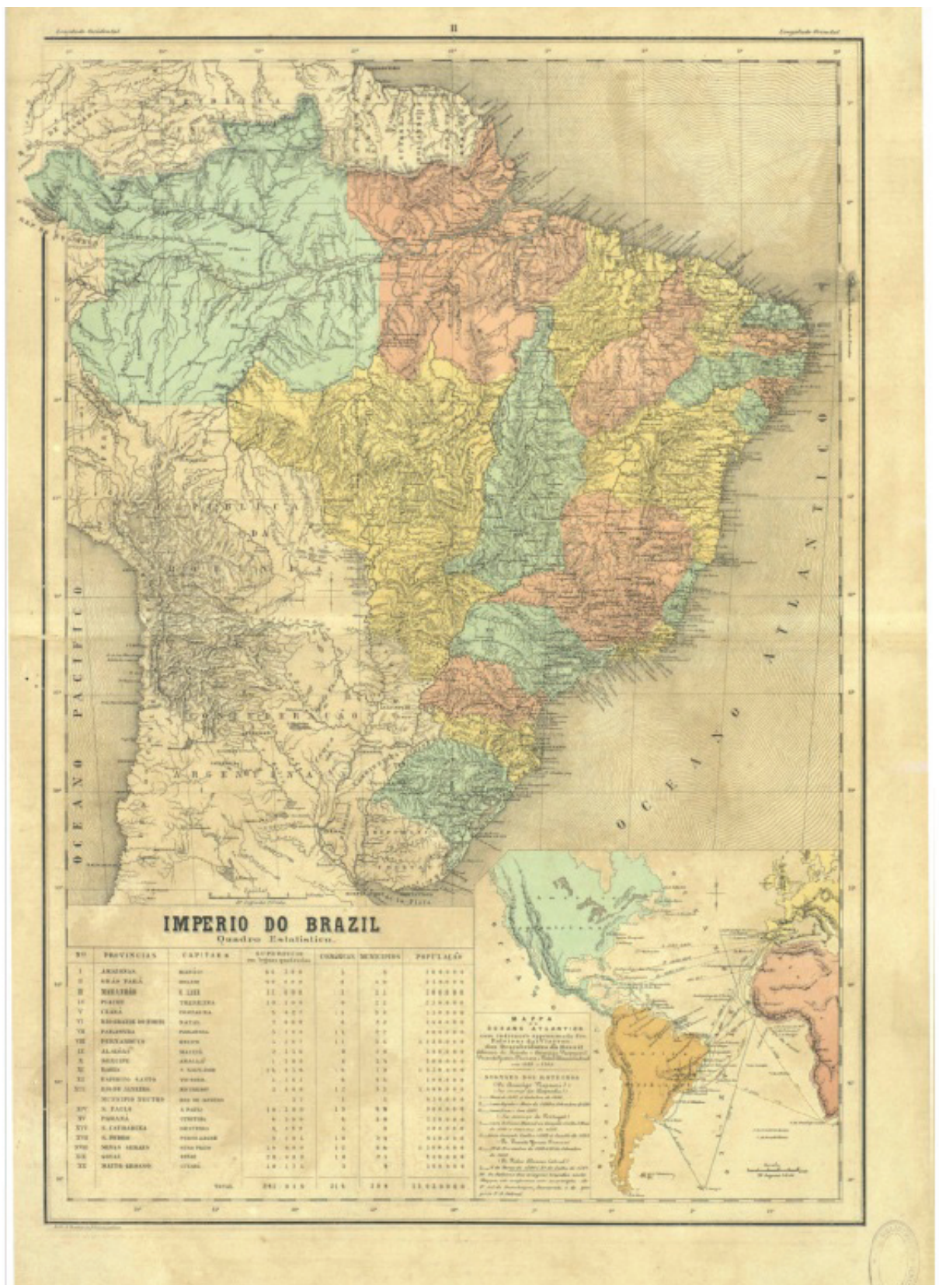

Figura 2. Império do Brasil - quadro estatístico. Candido Mendes de Almeida. Fonte: Atlas do Imperio do Brazil. Rio de Janeiro, Lithographia do Instituto Philomathico, 1868, p. 40.

Fonte: Biblioteca digital do Senado <http://www2.senado.leg.br/bdsf/item/id/179473> Acesso 02 de janeiro de 2013. 
A porção fronteiriça, em especial, com os territórios da Bolívia, Paraguai e Argentina, revela uma explicitação mais detalhada dos limites envolvendo esses Estados nacionais com o Brasil. A leitura permite inferirmos que o cartógrafo definiu com mais precisão as fronteiras, enfatizando os limites políticos.

Por último, é preciso indicar a presença de identificação de parte dos oceanos Pacíficos a oeste do território americano e do Atlântico banhando a costa leste do território brasileiro. No lado esquerdo, porção inferior da folha, encontra-se uma tabela com um quadro estatístico do Império do Brasil. Esse dispositivo reforça e completa informações que estão territorializadas no mapa. O quadro apresenta as províncias identificadas com algarismos romanos, nome das capitais, a superfície, as comarcas, os municípios e número de habitantes em quantias arredondadas. No lado direito, na porção inferior da folha, encontra-se Um mappa do Oceano Atlântico com a indicação approximada dos roteiros de Viagens dos descobridores do Brasil (Alonso de Hoeja e Americo Vespucci Vicente Yanez Pinzon e Pedro Álvares Cabral em 1499 e 1500). Essa figura apresenta uma régua de escala (léguas/gráos) e uma legenda cujo título é signaes dos roteiros. Marca essa representação cartográfica o desenho do contorno dos continentes, assim como o delineamento das rotas ensejadas pelos navegadores.

O terceiro mapa (Figura 3), intitulado Império do Brasil - divisão Eleitoral - (II B), expõe, com clareza, utilizando o jogo de cores, a localização dos distritos e províncias eleitorais. Apresenta, ainda (ao lado direito na porção inferior da folha), na forma textual, um quadro numerado identificando as províncias e distritos, assim como respectivos números de collégios, parochias e eleitores. Esse mesmo esquema está ladeado por outras duas imagens que, sob o título Montanhas do Brasil - notáveis por sua elevação, esquematizam, respectivamente, na forma de texto e de desenho, as características altimétricas do relevo do país. No lado esquerdo da figura, porção quase central, o autor apresenta um gráfico intitulado Rios do Brasil - notáveis pelo seu curso calculado em kilometros. Nitidamente há um esforço em sistematizar alguns aspectos das características locacionais e de extensões de fenômenos como os relacionados à hidrografia e topografia da nação. 


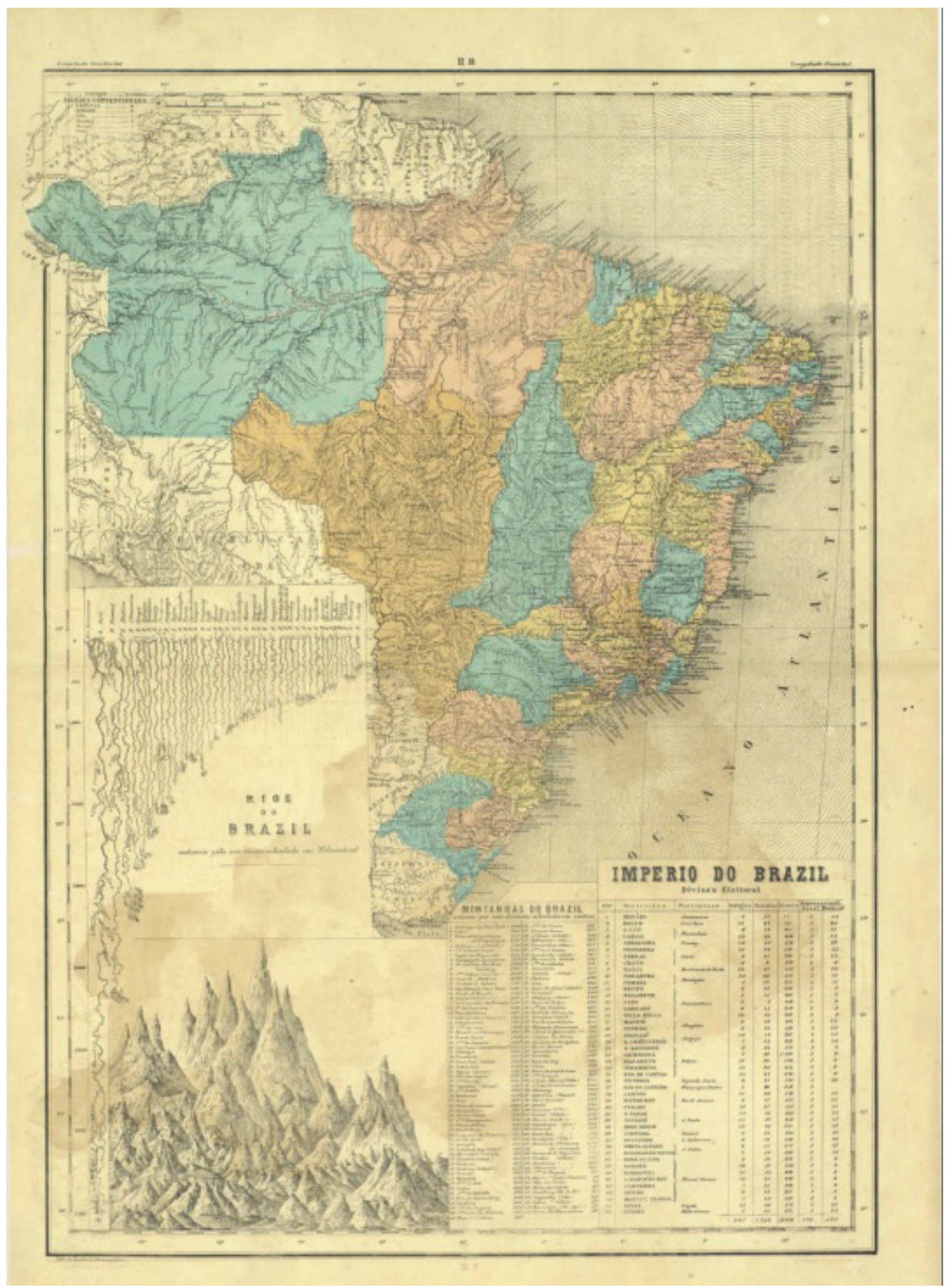

Figura 3. Império do Brasil divisão eleitoral Candido Mendes de Almeida. Fonte: Atlas do Imperio do Brazil.Rio de Janeiro, Lithographia do Instituto Philomathico, 1868, p. 41.

Fonte: Biblioteca digital do Senado <http://www2.senado.leg.br/bdsf/item/id/179473> Acesso 02 de janeiro de 2013. 


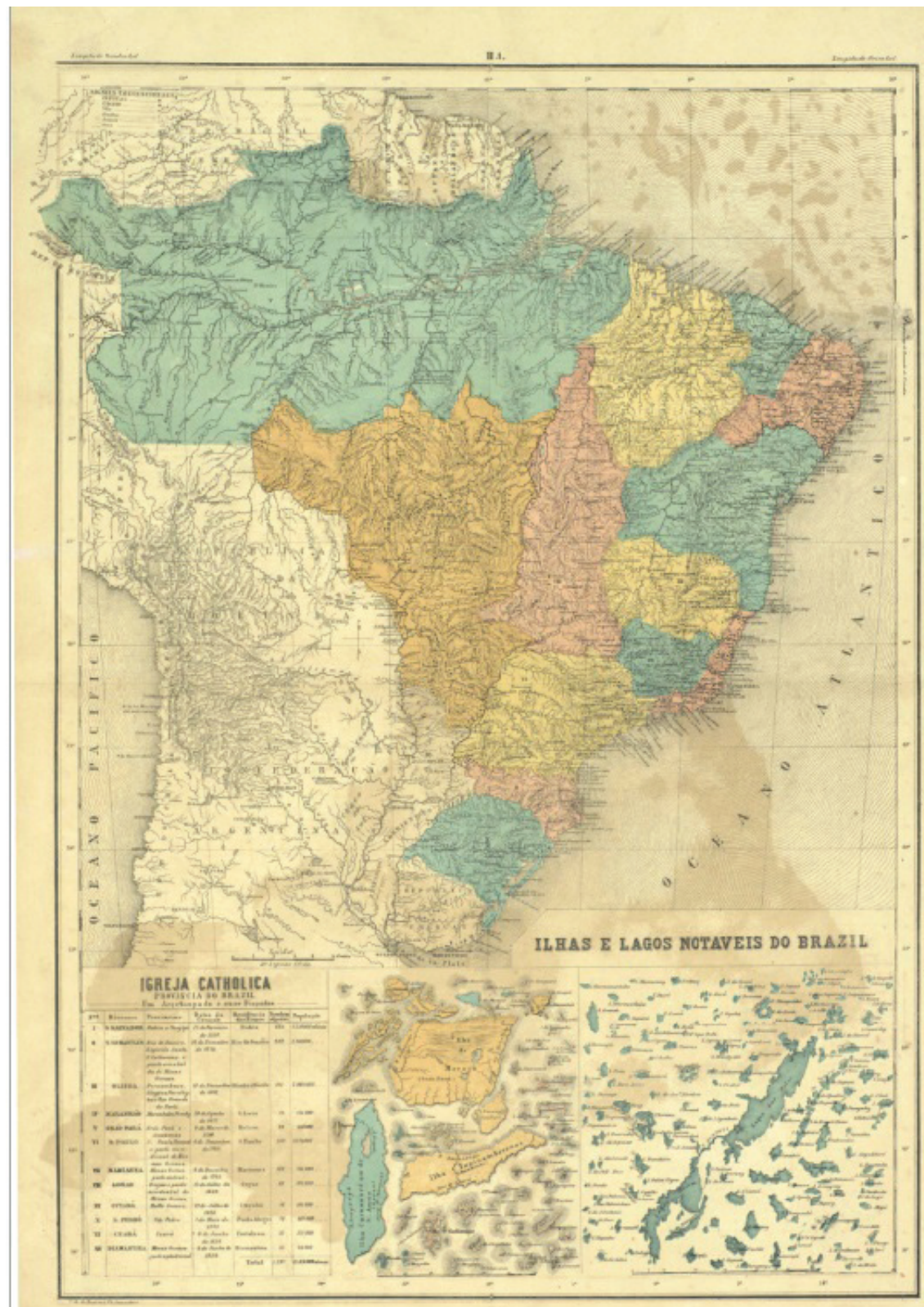

Figura 4. Igreja Catholica - Província do Brasil, um arçebispado e onze bispados. Candido Mendes de Almeida. Fonte: Atlas do Imperio do Brazil. Rio de Janeiro, Lithographia do Instituto Philomathico, 1868, p. 42.

Fonte: Biblioteca digital do Senado <http://www2.senado.leg.br/bdsf/item/id/179473> Acesso 02 de janeiro de 2013 
O quarto mapa (figura 4), intitulado Igreja Catholica - Provincia do Brasil (II A) apresenta uma divisão por regiões. Elas têm como referência o recorte territorial das dioceses. Tal classificação se complementa com o quadro localizado no lado esquerdo da porção inferior.

Nessa tabela (e no mapa) é possível observar a distribuição territorial das dioceses pelas províncias, resultando daí uma sobreposição de fronteiras que não necessariamente obedecem àquelas das unidades políticas do Império. No lado direito, na porção inferior da folha, está localizado um quadro intitulado Ilhas e Lagos Notáveis do Brasil. Nesse dispositivo encontramos as principais ilhas e lagos do Brasil, na forma de um desenho que não obedece a atributos de localização. É importante assinalar que os Estado-Nacionais vizinhos do Brasil estão devidamente identificados e localizados, assim como parte do Oceano Pacífico e Atlântico.

O quinto mapa (figura 5), intitulado Império do Brazil (mappa mudo), (II C), caracteriza-se por ser um material destinado às atividades escolares, como anuncia o Candido Mendes de Almeida (1868, p. 8) (grifo nosso) na introdução do material:

Julgamos também de interesse addicionar aquelles mappas [o mappa-mundi, administrativo, eclesiástico e eleitoral] outro com a mesma escala, com destino aos exames dos alumnos, apresentando em esqueleto ou mudo todo o nosso território: figurando sem nenhuma indicação escripta todos os objetos da Geographia physica e política, embora se consignassem os signaes dos respectivos povoados, conforme sua cathegoria [...].

Chama a atenção nessa imagem o fato de que a identificação dos Estados Nacionais que são vizinhos do Brasil não foi omitida, mesmo se tratando de um material destinado aos exames dos alunos. Além disso, como esclarece o autor (1868, p. 10). (Grifo nosso).,

este mappa he mudo quanto ao território do Brasil. Contém outro mappa [...] (no lado direito, porção inferior da folha), representando todos accidentes physicos do nosso planeta, quer na sua parte sólida, como na liquida, para instrucção dos alumnos; além de um, estatístico, dos paizes conterrâneos, indicando além das capitaes, a área, e população approximada, de cada um; [...]. 


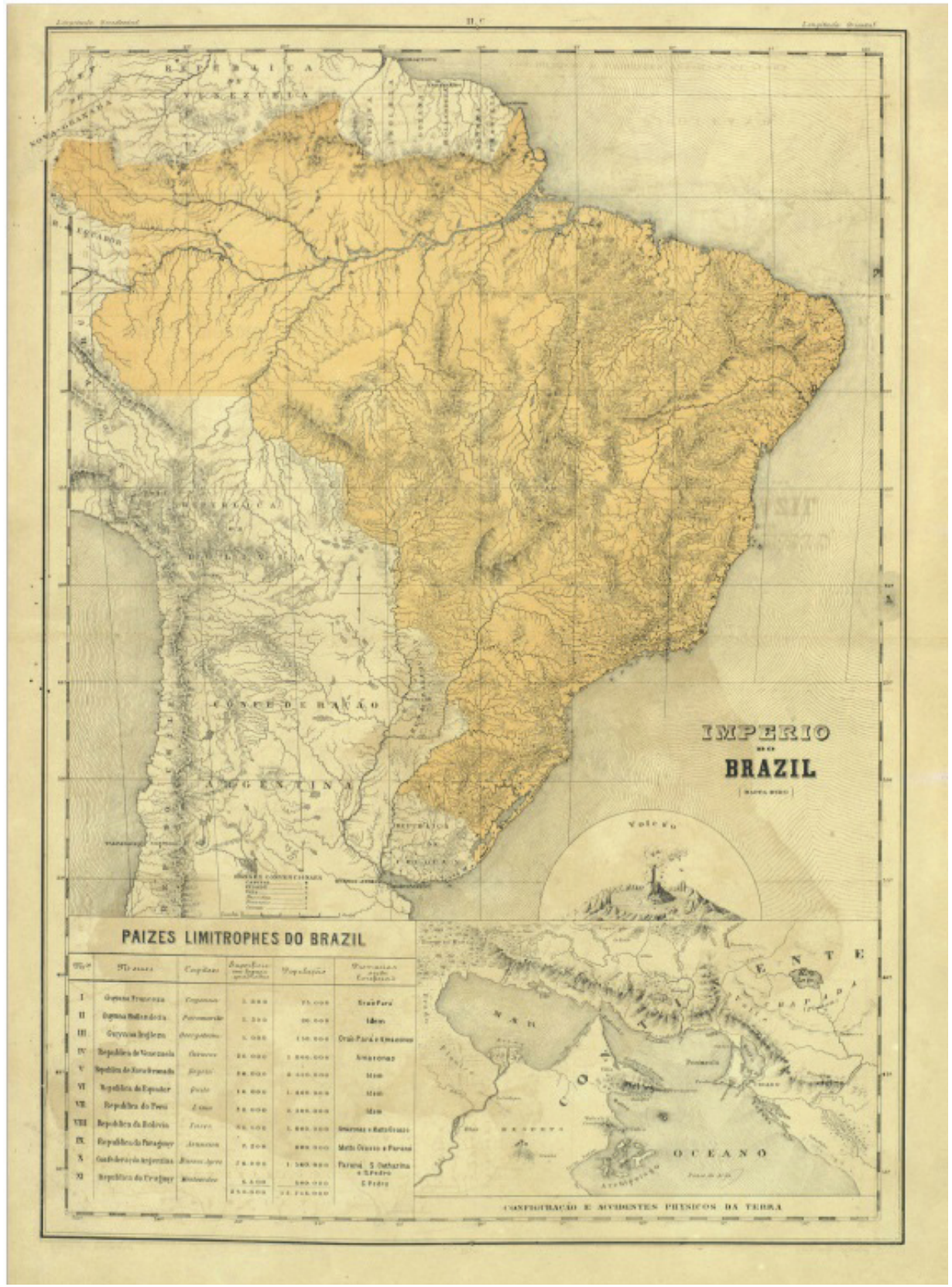

Figura 5. Imperio do Brasil (mappa mudo). Candido Mendes de Almeida. Fonte: Atlas do Império do Brazil. Rio de Janeiro, Lithographia do Instituto Philomathico, 1868, p. 43.

Fonte: Biblioteca digital do Senado <http://www2.senado.leg.br/bdsf/item/id/179473> Acesso 02 de janeiro de 2013. 
Após a descrição desse conjunto de mapas que caracterizam a primeira parte do Atlas do Imperio do Brazil, de Candido Mendes de Almeida, salta aos olhos o fato de que o autor, para ler o todo, produziu um recorte temático.

A segunda parte do Atlas é constituída de um elenco de mapas (isolados) de cada província, cuja escala gráfica utilizada nessas imagens apresentam variações. Identificamos a medida " 10 leguas de 20 ao grau" em algumas e em outras "40 léguas de 20 ao grau" o que caracteriza diferentes maneiras de detalhar os lugares. Acompanham esses mapas de cada província recortes que representam as plantas urbanas das capitais, incluindo também aquela do município neutro, capital do país, Rio de Janeiro. Nesses desenhos, há variações de unidades de medidas entre braças e palmos, resultando na mesma questão, no que se refere ao grau de minúcias que se desejou explicitar de cada lugar.

Para ambas as partes do trabalho, o autor apresenta, nas páginas iniciais, um roteiro intitulado Material e outros auxílios consultados e aproveitados nos mappas e plantas do atlas do Imperio do Brazil, (p. 9-35), com explicações detalhadas sobre as fontes consultadas. Vale ressaltar, ainda, que o último mapa reproduzido (p. 64) identifica uma província em projeto, a saber, Pinsônia (hoje Amapá). Essa elaboração retrata - como está evidenciado na legenda - uma leitura da correlação de forças políticas, pois demonstra um conhecimento das especificidades do lugar assim como uma intencionalidade de proposição, isto é, a criação de uma nova unidade política.

Nesse sentido vale destacar o que escreveu Black (2005, p. 120), (grifo nosso) a respeito dos atlas históricos e que nos ajuda adensar as reflexões sobre o documento em foco:

\begin{abstract}
Os atlas históricos [e geográficos] ofereciam exposições instrutivas de suas intenções, e essas, contidas principalmente em prefácios e introduções, são o guia mais importante para atitudes que condicionaram a compilação das obras. É um engano considerar os mapas sem um exame minucioso desses textos. Muito do que contém é superficial, repetitivo, evidente e bombástico, mas há também guias reveladores das intenções, razões para inclusão ou ênfase, e problemas encontrados. Se as seções de auto-referência dos atlas históricos [e geográficos] podem ser de auto-referência, elas são, no entanto cruciais à avaliação da mensagem visual dos mapas [...].
\end{abstract}

Com essas constatações e premissas, e em especial, acompanhando os ensinamentos de Harley (2005, p. 64/65) no que se refere ao tratamento de representações cartográficas, de que "la regla básica del método histórico es que solo se pueden interpretar los documentos en su contexto. Esta norma se aplica igualmente a los mapas, que deben llevarse de regreso al pasado y situarse estrictamente en su propio periodo y lugar [...]", o que podemos deduzir ? Uma possibilidade é que os mapas se articularam como uma estrutura discursiva, com expressividade, capaz de dar conta de demandas existentes no que se referia à compreensão da localização dos fenômenos administrativos, eleitorais e da religião católica em todas as paragens do país. 
Nesse ponto outra indagação se faz necessária: qual foi a fundamentação que levou o geógrafo a optar por esse critério classificatório para estruturar a sua leitura geográfica do Brasil? Provavelmente, a compreensão de que os elementos determinantes da vida da Nação (as questões de cunho operacional do Estado, tanto no plano administrativo como no definidor da ocupação das representações políticas junto às instituições, e o peso da Igreja) possuem uma localização que, ao ser sistematizada, proporciona entendimentos no plano material e simbólico.

Se averiguarmos novamente cada representação cartográfica, constataremos que elas manifestam a tentativa de colocar o Brasil e a América no cenário mundial, conforme sua territorialidade.

A Figura 1 - Mappa - mundi individualiza, na forma textual e depois na forma cartográfica, os continentes. Ao distinguir cada massa continental, reforça a posição da América e, por conseguinte, a do Brasil. Mesmo que esse desenho não apresente as individualidades nacionais delimitadas, o que se exibe é um conjunto de países que se localizam, harmonicamente, em cada porção continental.

O mappa-mundi, ao mesmo tempo em que veicula a posição de Estados Nacionais no globo, traça, de forma parametrizadora, aquilo que marca as suas diferenças perante os países vizinhos. É isso que podemos concluir quando constatamos que os demais mapas que apresentam o Brasil o fazem evidenciando suas fronteiras (Biaggi, 2011) com os países vizinhos.

Eles expressam um olhar sistematizador, delimitando e definindo fronteiras, como ponderou Raffestin (1993, p. 167):

no fundo trata-se da passagem de uma representação 'vaga' para uma representação 'clara', inscrita no território. A linha fronteiriça só é de fato estabelecida quando a demarcação se processa. 'De fato estabelecida' significa não estar mais sujeita à contestação por parte de um Estado que tivesse essa fronteira em comum. Pela demarcação elimina-se não um conflito geral, mas um conflito do qual a fronteira pudesse ser o pretexto. A linearização das fronteiras é uma tendência do Estado Moderno, que não foi desmentida desde o século XV. (1993, p. 167).

Essas referências indicam uma normatização do Estado no sentido de ordenar sua soberania, levando em conta as relações de poder relacionadas ao território e suas delimitações.

Tal colocação é confirmada pelo fato conhecido de que esse documento veio à tona, entre várias razões, vinculado às dificuldade existentes sobre o conhecimento das reais áreas pertencentes ao Brasil. Fato incrementado, como citado anteriormente, pela Guerra do Paraguai, tanto no plano correspondente à demarcação das fronteiras como no de apropriação simbólica.

A esse respeito é preciso pontuar que, embora sobre o Atlas do Imperio do Brazil tenham sido apresentados questionamentos quanto às linhas de fronteiras internas e entre 
nações ${ }^{1}$, ele foi admitido como uma referência nos estudos escolares e como fonte para o movimento de consolidação das fronteiras do Brasil, levado a cabo pelo Ministério das Relações Exteriores da época.

O segundo, terceiro e, quarto mapas, respectivamente, figuras n. ${ }^{\text {s }} 2,3$ e 4 são evidências de como a territorialização de dados estatísticos, eleitorais e administrativos, acompanhadas das suas respectivas distribuições geográficas, constituem modelos explicativos da realidade. Os dados estatísticos que vão se desdobrando no atlas e nas tabelas se vinculam a uma tendência comum entre os intelectuais no período em foco. A exemplo do que ocorria em França, no século XIX, como nos esclarece Revel (1989), no processo de consolidação do Estado Nacional francês, esperava-se que os dados numéricos fornecessem os elementos gerais para um estudo da sociedade. De forma lenta e gradual a legitimidade do aparato estatal foi se configurando, a articulação da autoridade e soberania do Estado passou a se expressar também pela representação simbólica entre poder e território.

Dessa maneira, pensando no quadro brasileiro da $2^{\mathrm{a}}$ metade do século XIX, essas informações estatísticas (também presentes em livros didáticos e outros impressos) quando devidamente tratadas a luz dos princípios estatísticos e cartográficos, cumpririam objetivos fundamentais na "invenção" (Ibidem, 1989) do território brasileiro, pois, concordando com o que escreveu Revel (ibidem, p. 136)," os dados que [...] [os estatísticos fornecem ] [...] tem apenas interesse porque estão vocacionados a serem agregados a nível nacional. O objetivo da Estatística Geral pressupõe espaço uniforme e impõe 'desterritorialização da descrição do mundo social'”' (grifo nosso).

Como já salientamos, ao se divulgar uma maneira de olhar para a expressão territorial da sociedade brasileira cria-se, por meio da imagem, a ideia de que a nação é a maneira como ela é representada. É um território que está se arrumando, via definições de fronteiras, assim como sua estruturação interna, que passa pela identificação de limites interprovinciais, localização de rios e tudo o mais que articule as diferentes dimensões que constituem a nação.

O território que se vê ordenado por meio do recorte regional eleitoral identifica e localiza para o leitor, em ambas as escalas, os lugares nos quais estavam ocorrendo correlações de forças relacionadas às temáticas "da centralização versus descentralização, legitimidade ou não do Poder Moderador e do Conselho de Estado e variantes eleitorais". (SANTOS, W. , 2002, p. 42).

Nesse sentido, um mapa do Imperio do Brazil cuja temática é a divisão eleitoral, torna-se um importante instrumento de reflexão sobre a política nacional. A territorialização desse fenômeno torna concreto em pensamento a distribuição geográfica desse processo. A identificação e localização de cada colégio eleitoral permitem dizer (ou reforçar) onde estão os setores responsáveis pelas decisões políticas no país.

1. Cf. Rodrigues (1978, p. 287 e ss.) 
O mapa que expressa a territorialidade da igreja Católica (figura 4) demonstra a força que essa instituição exercia no cenário brasileiro no momento. Acompanhado do quadro intitulado Igreja Catholica - província do Brazil um arcebispado e onze bispados, pode-se dimensionar territorialmente onde estão as dioceses. Deve-se atentar para a presença da Igreja Católica na vida pública do país. O fato de um documento de tal natureza conter informações (e, portanto, olhares) sobre onde estão as representações católicas, implica reconhecer a visão geoestratégica das relações de poder da Igreja no interior do Estado.

Esse mapa foi veiculado em meio à crise conhecida como da questão religiosa, como bem sintetiza Lopes (1997, p. 154):

Mais do que o simples episódio de cunho que envolveu os bispos do Norte e Nordeste do país, a questão religiosa se impôs tanto pelo clímax de um entrechocar-se de ideologias resultantes do regime de união entre a Igreja e o Estado, quanto pela expressão brasileira da oposição universal entre o ultramontanismo conservador e os progressos do liberalismo e do cientificismo que marcaram o período.

Independentemente dos seguimentos que se sucederam até culminar com a separação entre as duas entidades, o fato que nos interessa é o de que o cartógrafo, ao definir esse critério como fundante da leitura sobre o Brasil, transportou para seu trabalho uma concepção de mundo. Cândido Mendes de Almeida, ao oportunizar uma visão do conjunto brasileiro, levando em conta o papel da igreja, revela uma posição corporativa, como assinala Rodrigues (1978, p. 185): "a história da Igreja no Brasil encontra no Direito civil eclesiástico de Cândido Mendes de Almeida sua obra fundamental."

O professor de Geografia Candido Mendes deixa claro o papel que esse setor desempenhava nas decisões nacionais e, como seu trabalho se destinava fundamentalmente à juventude em formação, havia o interesse em transformar e reforçar (e ampliar), uma visão sobre a religião católica no país.

O mapa mudo (Figura 5), ao associar o trabalho didático ao reconhecimento toponímico de enseadas, rios, cumeadas de serras, lagoas, ilhas, capitais, cidades, vilas, paróquias, povoações, colônias, linhas de fronteira colocava em curso o reconhecimento do significado da imagem.

O que podemos inferir do trabalho com mapas mudos, é que ele se inscreve em um movimento maior, o da permanência de uma proposta cujos conteúdos e métodos estavam calcados na nomenclatura e memória. Sem abandonar a nomenclatura e uso da memória o que constatamos com essa proposição é que estava em curso a manutenção do viés naturalizante, buscando as harmonias que vão instando a leitura do Brasil e dos brasileiros pelo viés formalista.

O aluno ao completar as informações na figura do mapa passaria a preencher os vazios toponímicos que caracterizam a figura. E ao compor as partes desse todo, vai se configurando uma mensagem, que, segundo, Wood (2013, p. 30) "possuem um poder 
quase único para transmitir a ideia indefinida do Estado em forma concreta, tanto para os cidadãos quanto para outras nações."

\section{Considerações finais}

Nesse dimensionamento, o representante da Monarquia, na condição de deputado da província do Maranhão; detentor do título de bacharel em Direito, com um currículo identificado nas questões educacionais com larga experiência em ministrar aulas de Geografia e História, elaborou um estudo no qual a veiculação da visão de um setor da sociedade tornou-se a perspectiva (uniforme) de como se deveria fazer para compreender a geografia do Brasil.

À luz de um sujeito que ampliou a fundamentação científica das leituras geográficas, em relação às existentes naquele momento, o Atlas do Imperio do Brazil diversificou por via da cartografia e de textos fonéticos, a racionalidade na construção da ideia de Brasil e dos brasileiros.

Ao objetivo claro do professor de ter por fim auxiliar a instrução da mocidade que frequenta os estabelecimentos "nacionaes de instrucções" (ALMEIDA, 1868, p. 7), secundária, soma-se aquele que identificamos ao longo deste trabalho, o atlas, por meio de uma condição que opera no plano cognitivo, fundamentou como se deve proceder na interpretação geográfica dos fenômenos.

Isso se alinha ao fato de que os sujeitos "ao produzir [em] um sistema de representações que simultaneamente traduz e legitima a sua ordem, [...] [...] instala[ram] também 'guardiões' do sistema que dispõem de uma certa técnica de manejo das representações e símbolos [...]. Baczko (1985, p. 299). (Grifo nosso). E, nesse sentido, os guardiões agiram de forma aguerrida na fabricação da identidade do território e da nação.

\section{Referências}

ALMEIDA, A. F. Os jesuítas matemáticos e os mapas da América portuguesa (17201748). Revista Oceano, Lisboa, n. 40, p. 79-92, out/dez. 1999.

ALMEIDA, C. M. Atlas do Imperio do Brazil - comprehendendo as respectivas divisões administrativas, ecclesiasticas, eleitoraes e judiciarias Rio de Janeiro, Lithographia do Instituto Philomathico, 1868. Disponível <http:/www2.senado.leg.br/bdsf/item/ $\mathrm{id} / 179473>$ Acesso em 2 de janeiro de 2013.

ANDERSON, B. Comunidades Imaginadas. São Paulo: Companhia da Letras. 2008.

BACZKO, B. Imaginação Social. In: GIL, F. Enciclopédia - Anthropos - Homem. Lisboa: Einaudi/Imprensa Nacional, 1985, n5, p. 296-332.

BIAGGI, E. M. As fronteiras nas cartas gerais do Brasil no século XIX: um Império no jogo das nações. Anais do I Simpósio Brasileiro de Cartografia Histórica, 2011, 
p.1-19. Disponível <https://www.ufmg.br/rededemuseus/crch/simposio/DE_BIAGGI_ ENALI_M.pdf> Acesso em 19 de abril de 2014.

BLACK, J. Mapas e História - Construindo imagens do passado. Bauru: Edusc, 2005.

CAVENAGHI, A. J. O atlas do Império do Brasil e as representações existentes no livro: "História da vida privada no Brasil: Império: a corte e a modernidade nacional". Revista Projeto História. São Paulo, no 41, p. 383-403, dezembro de 2010.

CERTAU, M de. A invenção do cotidiano. A Arte de Fazer. $3^{\mathrm{a}}$ ed., Petrópolis: Vozes, 1998.

CHARTIER, Roger. A História Cultural - entre Práticas e representações. Lisboa: Difel, 1990.

CIPINIUK A. A face pintada em pano de linho - moldura simbólica da identidade brasileira. Rio de Janeiro: Editora PUC-RJ/Edições Loyola, 2003

DARDEL, E. O homem e a terra: natureza da realidade geográfica. São Paulo: Editora Perspectiva, 2011.

ENDERS, Armelle. “O Plutarco Brasileiro”: produção dos Vultos Nacionais no Segundo Reinado. Estudos Históricos, Rio de Janeiro, v. 14, n. 25, p. 41-62, 2000. Disponível $<$ http://bibliotecadigital.fgv.br/ojs/index.php/reh/article/download/2114/1253> Acesso em 01 de setembro de 2013.

HARLEY, J. B. Textos y contextos em La interpretación de los primeros mapas In HARLEY, J. B. La Nueva Naturaleza de los Mapas: Ensayos sobre la Historia de la Cartografia. Fondo de Cultura Económica: México, 2005, p. 59-78.

JACOB, C. Toward a Cultural History of Cartography, Imago Mundi 48 (1996): 191-198

LEFEBVRE, H. Lógica Formal / Lógica Dialética. $3^{\mathrm{a}}$ ed., Rio de Janeiro: Civilização Brasileira, 1987.

LOPES, M. M. O Brasil descobre a pesquisa cientifica-os museus e as ciências naturais no século XIX. São Paulo: Hucitec, 1997.

MAUAD, A. M. Imagem e auto-imagem do Segundo. In: ALENCASTRO, L. F. (org.). Império: a corte e a modernidade nacional - História da vida privada. São Paulo: Companhia das Letras, 1999, volume 2

MOREIRA, R. O círculo e a espiral: para a crítica da Geografia que se ensina . Niteroi: Edições AGB Niterói,2004.

NAXARA, M. R. C. Cientifismo e sensibilidade Romântica - em busca de um sentido explicativo para o Brasil no século XIX. Brasília: UNB, 2004.

PEIXOTO, R. A. A Carta Niemeyer de 1846 e as condições de leitura dos produtos cartográficos. In Anos 90,(UFRGS. Impresso) Porto Alegre, v. 11, n. 19/20, jan./dez. 2004, p.299-318. Disponível <http://www.seer.ufrgs.br/index.php/anos90/article/ view/6359> Acesso 24 de outubro de 2013. 
OLIVEIRA, Lúcia L. A Questão Nacional na Primeira República. São Paulo: Brasiliense, 1990.

RAFFESTIN, C. Por uma Geografia do Poder. São Paulo: Ática, 1993.

RAISZ, E. Cartografia Geral. Rio de Janeiro: Científica, 1969.

REVEL, J. A. Invenção da Sociedade. Lisboa: Difel.1989.

REVISTA DO INSTITUTO HISTÓRICO E GEOGRÁPHICO DO BRASIL. Parecer da Commissão de trabalhos geográficos a que se refere o parecer anterior. Tomo XXXII, 1869, p. 296-298

. Extrato dos estatutos do Instituto Histórico e Geográphico Brasileiro. Tomo I, 2.-Trim., 1839, n. 1.

RODRIGUES, J. H. Teoria da Historia do Brasil. São Paulo: Companhia Editora Nacional/MEC, 1978.

SANTIROCCHI, I. D. A coragem de ser só: Cândido Mendes de Almeida, o arauto do ultramontanismo no Brasil. Revista Almanak. Guarulhos, n.07, p.59-80, $1^{\text {o }}$ semestre de 2014.Disponível <http://www.almanack.unifesp.br/index.php/almanack/issue/view/20/ showToc $>$ Acesso 02 de janeiro de2015.

SANTOS, D. A Geograficidade da Escola e o Ensino de Geografia. Revista Tamoios, São Gonçalo (RJ), ano 10, n. 1, págs. 17-29, jan/jun. 2014.Disponível<http://www.epublicacoes.uerj.br/index.php/tamoios/article/view/11626/9586>Acesso 23 de fevereiro de 2014

SANTOS, W. G. dos. Roteiro bibliográfico do pensamento político-social brasileiro (1870-1965). Belo Horizonte: UFMG/Casa de Oswaldo Cruz, 2002.

SILVA, J. L. B Atlas Geográfico do Brasil - Leituras da territorialidade e a construção da brasilidade. Tese de Doutorado. Programa de Pós Graduação de Ciências Sociais. PUCSP. 2006.

THIÈSSE, A. M. As identidades nacionais - Um paradigma transnacional. In GAUDIO, R. S. D.; PEREIRA, D. B. (orgs.) Geografias e Ideologias - submeter e qualificar. Belo Horizonte: Editora UFMG. 2014, p.33-65.

WOOD, D. Dogma visualizado. Estado-nação, Terra, Rios. In CAZETTA, V. OLIVEIRA Jr., W.M.de. Grafias do espaço - imagens da educação geográfica contemporânea. Campinas: Alínea Editora. 2013.

Este artigo é fruto de desdobramentos vinculados à tese de doutoramento desenvolvida junto ao Programa de Pós-graduação em Ciências Sociais da Pontifícia Universidade Católica de São Paulo(PUCSP), defendida em maio de 2006. 
Jorge Luiz BARcelllos da Silva

Graduado em Geografia pela Universidade Federal do Rio Grande do Sul (UFRGS). Mestrado em Geografia Humana pela Universidade de São Paulo (USP). Doutorado em Ciências Sociais pela Pontifícia Universidade Católica de São Paulo ( PUCSP). Atualmente é professor adjunto II da Escola de Filosofia, Letras e Ciências Humanas da Universidade Federal de São Paulo (UNIFESP).

Endereço: Estrada do Caminho Velho, 333 - Pimentas, Guarulhos - SP, 07252-312 E-mail: jorge.barcellos@unifesp.br

Recebido para publicação em julho de 2015 Aprovado para publicação em janeiro de 2016 